\title{
Electronic service quality in higher education: Evidence from Albania
}

\author{
Dr. Shpëtim Çerri \\ Faculty of Economics, University "Aleksandër Xhuvani” \\ Elbasan. Albania \\ shpetim.cerri@uniel.edu.al
}

\section{ABSTRACT}

The purpose of this paper is to investigate the electronic service quality (e-SQ) offered by a higher education institution in Albania. Many universities are implementing web-based solutions to facilitate the delivery of their services, previously offered by appointed staff and physical facilities. These electronic services aim to increase the effectiveness of university's activities as well as to increase the convenience and the quality that both students and faculty receive. This study employs a modified E-S-Qual scale to measure the perceived service quality offered by a public university in Albania. Exploratory factor analysis and multiple regression analysis were used to confirm the proposed factor structure, while ANOVA served to measure the differences in e-SQ perceptions between students and faculty. The data analysis reveals interesting findings about the e-SQ offered by the university, as well as highlights the differences in perceptions between students and faculty. The study also affirms the E-S-Qual scale as a suitable instrument for measuring the e-SQ in higher education institutions. The results of the study are helpful for university management as they provide an overview of actual conditions of the quality the university offers and serve as a benchmark for further improvements. A limitation of this paper is that it focuses in measuring the e-SQ in a single setting. Nevertheless, this does not compromise the generalizability of the results and encourages the replication of this kind of study with further research.

KEYWORDS - Electronic service quality, web-site, higher education, Albania.

\section{Introduction}

The widespread use of the Internet has expanded also in public services, moving the traditional face-to-face encounter to online self-service models. This trend has also embraced universities, which have their own web pages, offering a wide range of information, services, and other online facilities. Today, a good proportion of overall services that universities offer come to students and faculty through electronic channels.

But, in an online environment, achieving superior service quality is very challenging task. Researchers and practitioners have sought to understand how individuals perceive and evaluate the websites and the service quality offered in online settings. Services offered via websites aim to meet the consumer's desire for convenience and cost savings. Elliot and Fowell's (2000) have found that online service experience can be damaged by many website attributes, such as lack of customer service's responsiveness, difficulties in website navigation, web site complexity, and security concerns. Thus, measuring service quality in online setting is of imperative importance for companies or institutions that deliver services through technology-based channels. Through the years researchers have developed scales like SERVQUAL (Parasuraman et al., 1988) or SERVPERF (Cronin and Taylor, 1994) for measuring service quality, but they have been conceptualized for traditional, face-to-face contexts. With the emergence of online services, other scales were developed for measuring online service quality, like E-S-Qual (Parasuraman et al., 2005), E-A-S-Qual (Kim et al., 2006), WebQual (Loiacono et al., 2000), PIRQUAL (Francis and White, 2002). e-SELFQUAL (Ding et al., 2011), etc. This study aims to contribute in the measurement of online service quality offered by a public education institution using a modified E-S-Qual scale. Although originally developed for measuring e-SQ provided by a retailing website, it allows to modify its measurement items according to specific contexts. The data were gathered in a public university in Albania, both from students and faculty. Exploratory factor analysis was used to uncover the underlying structure of online service quality dimensions, while multiple regression analysis determined the relative impact of each dimension. Finally, ANOVA analysis was employed to reveal the differences in online service quality perceptions between students and faculty. 


\section{Literature review}

\section{Service quality}

Service quality has been a predominant topic in services marketing for more than three decades. In 1980 Lehtinen and Lehtinen coined their model of service quality, where they conceptualized it as comprised of three dimensions: physical quality (the quality of physical elements of service), interactive quality (the quality of interaction between customer and other elements of service experience), and corporate quality (the quality dimension which is developed through the years of existence of a service company). Gronroos (1984) proposed that service quality has two distinct dimensions: technical quality and functional quality. Technical quality relates to the outcome, or what the customer receives from a service encounter, while functional quality relates to the process of how customer receives the service. Parasuraman et al. (1988) identified five dimensions of service quality, which are (1).Tangibles: physical facilities, equipment and appearance of personnel; (2) Reliability: ability to perform the promised service dependability and accurately; (3) Responsiveness: willingness to help customers and provide prompt service; (4) Assurance: knowledge and courtesy of employees and their ability to inspire trust and confidence; and (5) Empathy: caring, individualized attention that a firm provides to its customers. Regardless the number of dimensions, in general all the researchers agree that service quality stems from a comparison between what customers expect to receive from a company and the company's actual service performance.

\section{Electronic service quality}

As technology has shaped our lives and naturally the way the firm's are conducting business, electronic marketing activities have gained a lot of attention. Delivering services through electronic channels is quite different from traditional face-to-face delivery. Zeithaml et al. (2000) proposed that electronic services are web services delivered through the Internet. In the online environment, companies must shift their focus from traditional dimensions of service quality to e-SQ dimensions, in order to keep their customers satisfied and loyal (Parasuraman et al., 2005). E-SQ relates to all the steps that a consumer goes through during his/her interaction with a website: the degree to which a website facilitates efficient and effective online experience. Santos (2003) proposed that e-SQ had these dimensions: appearance, ease of use, efficiency, linkage, content, structure, incentive, security, communication, reliability, and customer support. Zeithaml et al. (2000) explored a variety of website attributes, like search engines, tab structuring, one click ordering perceived ease of finding what user is looking for, perceived transaction speed, ease of navigation in general, responsiveness to customer needs, etc. They concluded that consumer' assessments of a website's quality stems not only from their experiences during their interactions with the website but also from post-interaction aspects of the service. The theoretical framework proposed by Parasuraman et al., (2005), depicted in Figure 1, represents the cognitive structures of consumers, and how they retain product information in their memory at multiple levels of abstraction.

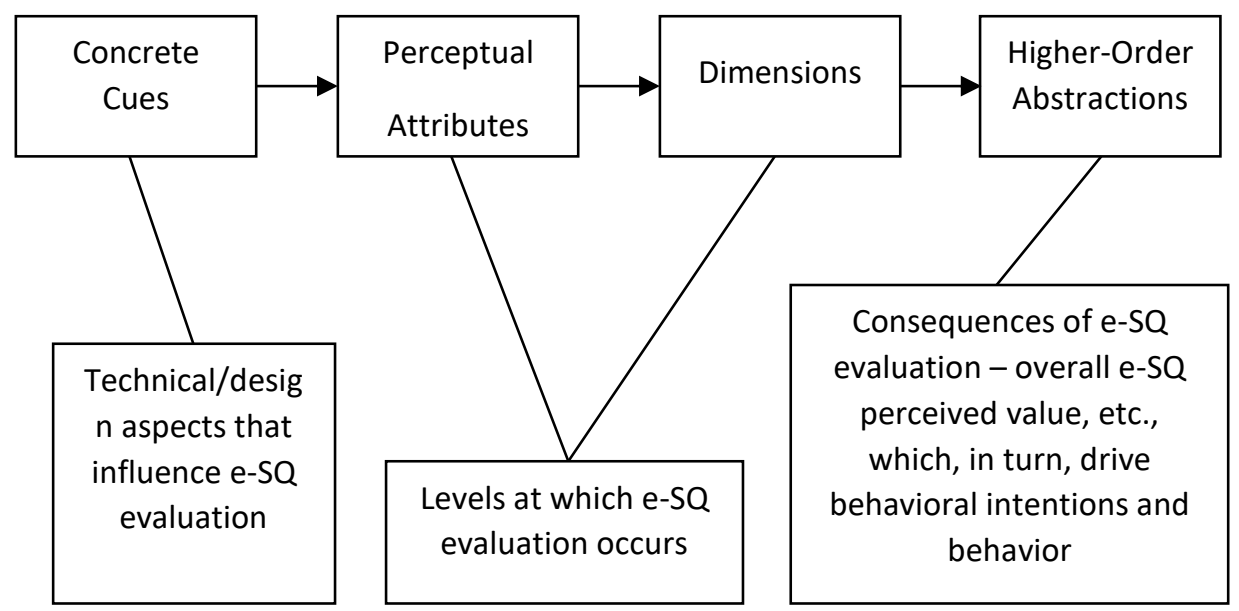

Figure 1: The framework for understanding the domain and consequences of e-service quality (adapted from Parasuraman et al, 2005) 
ISSN 2411-9563 (Print) ISSN 2312-8429 (Online)
European Journal of Social Sciences Education and Research
September-December 2014

Volume 1, Issue 2

\section{The measurement of e-service quality}

Loiacono et al. (2000) proposed Web-Quality, a scale for rating websites on 12 dimensions: interaction, informational fit to task, flow-emotional appeal, trust, response time, design, business processes, intuitiveness, visual appeal, innovativeness, integrated communication, and substitutability. They found that only some dimensions, like visual appeal, interaction, and integrated communications, significantly influence perceived e-SQ. Barnes and Vidgen (2002) developed a multi-item scale based on the weighted importance of five factors: information, design, usability, trust, and empathy, while Francis and White (2002) proposed PIRQUAL scale, which measured e-service quality based on web site, transaction system, delivery, customer service, and security. Parasuraman et al. (2005) developed E-S-QUAL scale to measure the e-SQ provided by a retailing website. It followed the previous work of Zeithaml et al. (2002), who identified five service quality dimensions relevant to commercial websites: ease of navigation, efficiency, security, flexibility, and site aesthetics. E-S-QUAL measures e-SQ using 22 items, based on four dimensions identified by Parasuraman et al. (2005) as efficiency, system availability, fulfillment, and privacy. Efficiency refers to the ease and speed of accessing and using the site; system availability is the extent to which the site's promises about order delivery and item availability are fulfilled; system availability is associated to the correct technical functioning of the site; and privacy includes the degree to which the site is safe and protects customer information (Parasuraman et al., 2005). Cristobal et al. (2007) constructed a new scale named PeSQ which measured e-service quality based on customer service, web design, assurance, and order management, while Ding et al. (2011) proposed e-SELFQUAL, conceptualized on four e-service quality dimensions: perceived control, service convenience, customer service, and service fulfillment.

Due to the fact that E-S-Qual has reflected good reliability and validity across many studies, this paper uses a modified ES-Qual scale to investigate e-service quality in higher education institutions. Some items were modified or excluded from the original scale in order to comply with the specifics of electronic services offered by universities. Since the services offered by university's websites aim both students and faculty, this paper also tries to uncover the differences in e-service quality perceptions between these two groups of users. Thus, the research question are as follows:

RQ1: Which is the relative impact that each of the dimension of Parasuraman et al. (2005) model has on higher education e-SQ?

RQ2. Which are the differences, according to each dimension, between student users and faculty users?

\section{Research methodology}

The items for measuring e-SQ in this study were adapted from the E-S-Qual scale developed by Parasuraman et al. (2005). Since the original scale was constructed for use in retailing websites, its items had to be modified in order to be usable in the context of this research. Table 1 presents the four dimensions of e-SQ and the construct of e-SQ, as well as the items used for measuring each of the construct. The questionnaire developed contained 19 pairs of statements for measuring respondents' expectations and perceptions on efficiency, system availability, fulfillment, privacy, and overall e-SQ (Table 1). The respondents were asked to indicate their level of disagreement/agreement with the questionnaire statements in a 7 point Likert scale. The data were gathered asking students and faculty members in a public university in Albania, located at the central region of the country. 300 questionnaires were distributed and 281 were returned completed, achieving a response rate of $93.6 \%$. From 281 useful questionnaires, 195, or $69 \%$, were completed by students and 86 questionnaires, or $31 \%$, by faculty members. The data were gathered from a team of interviewers through face interviews with members of the target population.

Table 1: e-SQ dimensions and respective measurement items

\begin{tabular}{|l|l|}
\hline $\begin{array}{l}\text { Electronics Service } \\
\text { quality dimensions }\end{array}$ & Respective statements (Measurement items) \\
\hline Efficiency & EFF1: I can easily find what I need in my university's site \\
\hline & EFF2: It makes it easy to get anywhere on the site \\
\hline & EFF3: University's site enables me to quickly perform what I intend to do \\
\hline & EFF4: The information in my university's site is well organized \\
\hline & EFF5: The pages load fast \\
\hline & EFF6: The site is simple and user-friendly \\
\hline & EFF7: The site is well organized \\
\hline
\end{tabular}


ISSN 2411-9563 (Print) ISSN 2312-8429 (Online)
European Journal of Social Sciences Education and Research
September-December 2014

Volume 1, Issue 2

\begin{tabular}{|l|l|}
\hline System availability & SUS1: The site is always available \\
\hline & SUS2: The site launches and runs right away \\
\hline & SUS3: The university's site does not crash \\
\hline Fulfillment & FIL1: The site updates the information regularly \\
\hline & FIL2: The information provided in university's site is suitable for my needs \\
\hline Privacy & FIL3: The university's site has made my life easier \\
\hline & PRI1: The site protects the my sensitive information \\
\hline & PRI2: It does not share my personal information with other sites \\
\hline $\begin{array}{l}\text { Overall } \\
\text { quality }\end{array}$ & PRI3: I think that my university's site is very secure \\
\hline
\end{tabular}

The first step in data analysis was scale purification. The data set was checked for the existence of missing values, normality, and outliers. The missing values were replaced using multiple imputation method in IBM SPSS 22.0, while very few outliers were present. The data resulted linear, and the values of skewness and kurtosis were within the acceptable range. Then, exploratory factor analysis (EFA) was conducted, in order to assess the dimensionality of the scale used in the study. Exploratory factor analysis is an inter-dependency technique that researchers use to determine the underlying structure between variables in a statistical analysis (Hair et al., 2009). After conducting EFA, the overall factor solutions resulted in good loading patterns and explain $71.673 \%$ of the variation; also the factor structure fitted with the proposed instrument.

The next step in data analysis process was conducting confirmatory factor analysis (CFA). CFA is used by researchers to further evaluate the dimensionality, reliability and validity of the generated structure of factors. CFA aims to determine if the number of factors and respective loadings of measured variables are in concordance with what is expected from the literature (Brown, 2006). Reliability was evaluated through the standardized Cronbach's alpha (Cronbach, 1951), referring to Nunnally (1978) who suggests that a scale with alpha greater than 0.7 is considered as reliable. After examining every dimension, the Cronbach's alpha was calculated for every distinct construct generated from factorial analysis. The final Cronbach's alpha of all items varied from 0.733 to 0.849 , suggesting good internal consistency between items of every construct and construct reliability. Also, the combined scale reliability for the 19 items is 0.911 , reflecting acceptable reliability and convergent validity (Hair et al., 2009). Factor structure was also considered as stable. Overall, the proposed model had very good reliability and validity (both convergent and discriminant) indicators.

\section{Data analysis and results}

RQ1: Which is the relative impact that each of the dimension of Parasuraman et al. (2005) model has on higher education e-SQ?

After confirming the factor structure, dimensionality, reliability, and validity of the five constructs, multiple regression analysis was performed in order to uncover the relative impact of each dimension on e-SQ in higher education. Overall e$S Q$ served as dependent variable, while efficiency, system availability, fulfillment, and privacy served as independent variables. The analysis was performed using IBM SPSS 22.0 software, and a summary of results is presented in Table 2.

Table 2: Regression analysis results

\begin{tabular}{|l|l|l|l|l|l|}
\hline Construct & $\begin{array}{l}\text { Beta } \\
\text { coefficient }\end{array}$ & Standard error & t-value & Significance & VIF \\
\hline Constant & 0.059 & 0.043 & 1.578 & 0.000 & 2.214 \\
\hline Efficiency & 0.208 & 0.011 & 2.658 & 0.000 & 1.695 \\
\hline System availability & 0.137 & 0.067 & 0.338 & 0.000 & 1.337 \\
\hline
\end{tabular}


ISSN 2411-9563 (Print) ISSN 2312-8429 (Online)
European Journal of Social Sciences Education and Research
September-December 2014

Volume 1, Issue 2

\begin{tabular}{|l|l|l|l|l|l|}
\hline Fulfillment & 0.223 & 0.034 & 2.985 & 0.004 & 2.647 \\
\hline Privacy & 0.112 & 0.029 & 0.915 & 0.007 & 2.109 \\
\hline $\mathrm{R}^{2}$ & 0.644 & & F-statistics & 16.587 & \\
\hline Adjusted $\mathrm{R}^{2}$ & 0.621 & & $\begin{array}{l}\text { Significance (F- } \\
\text { statistics) }\end{array}$ & 0.000 & \\
\hline
\end{tabular}

As it can be seen from Table 2, there is a significant relationship between the four dimensions of e-SQ and overall higher education e-SQ ( $F=16.587$, significance of $F<0.001)$. Furthermore, these four dimensions explain a considerable proportion of the variance in higher education e-SQ, $64.4 \%$, as indicated by $R^{2}$ value and adjusted $R^{2}$ of $62.1 \%$. All four dimensions were found as significant predictors of overall higher education e-SQ. Fulfillment was the most influential determinant $(\beta=0.223, p=0.004)$, followed by Efficiency $(\beta=0.208, p=0.000)$, System availability $(\beta=0.137, p=0.000)$, and Privacy $(\beta=0.112, p=0.007)$.

Table 2 also presents the VIF (Variance Inflation Factor) values for the regression analysis conducted. VIF is a good indicator useful for multicollinearity check in statistical analysis (Hair et al., 2009). Multicollinearity is the degree at which a construct can be explained by other constructs in the analysis (Hair et al., 2009), i.e. it refers to the situation where independent/predictor variables are highly related to each - other $(\mathrm{Ho}, 2006)$ and could lead to drawing wrong conclusions and making type II errors (paths do not result significant when in fact they are) (Grewal et al., 2004). VIF the ration between the total standardized variance and unique variance. If the first one is 10 times larger than the second, i.e. if construct VIF is greater than 10, then the multicollinearity between independent variables is present (Hair et al., 2009). As Table 2 shows, the VIF values vary from 1.337 to 2.647 , much lower than the threshold of 10 , indicating the lack of multicollinearity among regression constructs.

RQ2. Which are the differences, according to each dimension, between student users and faculty users?

The second research question of the study relates to the differences that exist between bachelor level and master level students, for each of the dimensions of service quality, as well as for the overall HE service quality. Table 3 presents the descriptive statistics and the results of ANOVA analysis regarding this research question:

Table 3: ANOVA results for differences between student users and faculty users of university's webpage

\begin{tabular}{|l|l|l|l|l|l|l|l|}
\hline & \multicolumn{6}{|l}{ Descriptive statistics } & \multicolumn{2}{l|}{ ANOVA } \\
\hline Dimension & N & Mean & Min & Max & $\begin{array}{l}\text { Degrees of } \\
\text { freedom }\end{array}$ & F & Sig. \\
\hline Efficiency & & & & & 1 & 14.362 & 0.000 \\
\hline Students & 195 & 3.78 & 1.84 & 5.15 & & & \\
\hline Faculty & 86 & 3.42 & 1.61 & 4.67 & & & \\
\hline System availability & & & & & 1 & 8.187 & 0.001 \\
\hline Students & 195 & 3.84 & 2.19 & 4.55 & & & \\
\hline Faculty & 86 & 3.67 & 1.81 & 4.33 & & & \\
\hline Fulfillment & & & & & 1 & 8.681 & 0.000 \\
\hline Students & 195 & 2.61 & 1.17 & 3.66 & & & \\
\hline Faculty & 86 & 2.15 & 1.07 & 3.21 & & & \\
\hline Privacy & & & & & 1 & 10.249 & 0.000 \\
\hline Students & 195 & 3.54 & 2.42 & 5.03 & & & \\
\hline
\end{tabular}


ISSN 2411-9563 (Print) ISSN 2312-8429 (Online)
European Journal of Social Sciences Education and Research
September-December 2014

Volume 1, Issue 2

\begin{tabular}{|l|l|l|l|l|l|l|l|}
\hline Faculty & 86 & 3.17 & 2.24 & 4.81 & & & \\
\hline Overall e-SQ & & & & & 1 & 10.982 & 0.004 \\
\hline Students & 195 & 3.39 & 2.39 & 4.57 & & & \\
\hline Faculty & 86 & 3.11 & 2.27 & 3.72 & & & \\
\hline
\end{tabular}

As it can be concluded from Table 3, there are significant differences in perceptions between student users and faculty users of university's website for all the dimensions, as well as for overall e-SQ. Students rate website all dimensions higher than faculty member, as well as perceive website overall service quality to be better of what faculty perceive.

\section{Discussion and implications}

This study served to several purposes. It confirmed E-S-QUAL scale as a suitable tool for measuring e-SQ in higher education settings. Its modified statements are able to fully grasp the nature and the essence of universities' website service quality. The four e-SQ dimensions of Parasuraman et al. (2005) scale were found to be also applicable in the higher education settings, reflecting good dimensionality, reliability and validity. The dimensions explained a good proportion of the variance in e-SQ, where fulfillment was the most influential determinant, followed by efficiency, system availability, and privacy.

One of the most important benefits that technology offers to humans is convenience, allowing them to perform tasks and receiving what they need easily and in timely manner. Fulfillment dimension reflect this aspect of website, providing users the right, updated information suitable for their needs. Granting access to university's services at any time and any place is widely appreciated by website users, since it results in time and costs (of any form) savings. Efficiency was found to be the second most important dimensions of a university's website. It relates to the way a website user finds the site easy to use and navigate. The structure of a page, the way the information is placed in respective sections, the speed of loading and how user-friendly it is, are the most common features that university's website users are keener to judge. System availability was also found to be a significant driver of e-SQ in university's website, so people responsible for running the website (like IT department) must ensure to have the site always smoothly running. Finally, privacy dimension, although ranked as the last influential dimension of e-SQ, is considered by respondents as relatively important in evaluating university's website quality. Since users' interaction with this kind of website does not include monetary transactions or providing credit card information, users feel more relaxed regarding privacy issues.

There were significant differences between student users and faculty users regarding all the dimensions of e-SQ, as well as regarding overall e-SQ of university's website. Faculty users found the quality of website better than student users, especially for fulfillment dimension (gap score $=0.46$ ), while the smallest gap resulted for system availability dimension (gap score $=0.17$ ). The gap for overall e-SQ between two groups of respondents is 0.28 , in a 7-point Likert scale. These significant differences in perceptions raise serious questions for the administrators of web-site, as well as for other persons responsible for the sources of information that make it updated and vivid. They seem to cater more for the needs of faculty users than for students, giving to the last smaller priorities. Another important finding is that mean scores for all the dimensions, for both groups, where smaller than 4 (which is considered as "neutral" evaluation in a 7-point Likert scale). This means that users found the website quality, along all dimensions, of poor quality. University's management and website administrators must make the necessary improvements to the website, focusing their efforts to the worst-perceived dimensions, like fulfillment and privacy.

Although focused only in one university, a fact that obviously constitutes a limitation for this study, it is a pioneering effort in evaluating e-SQ in a higher education setting. It helps universities to give the proper attention and importance to electronic services, as well as to measure and monitor e-SQ over time. By continuously measuring e-SQ website administrators will better understand what users evaluate most and what needs to be improved. Further studies can be carried out to confirm the appropriateness of E-S-QUAL scale in measuring e-SQ in a non-commercial website.

\section{Literature}

[1] Barnes, S.J., \& Vidgen, R.T. (2002). An integrative approach to the assessment of e commerce quality. Journal of Electronic Commerce Research, 3(3), 114-127. 
[2] Brown, T. A. (2006). Confirmatory factor analysis for applied research. The Guilford Press.

[3] Cristobal, E., Flavian, C., \& Guinaliu, M. (2007). Perceived e-service quality (PeSQ): measurement validation and effects on consumer satisfaction and web site loyalty. Managing Service Quality, 17(3), 317-340.

[4] Cronbach, L. J. (1951). Coefficient alpha and the internal structure of tests, Psychometrika, 16(3), 297-334.

[5] Cronin, J. J., \& Taylor, S.A. (1994). SERVPERF versus SERVQUAL: reconciling performance-based and perceptions-minus-expectations measurement of service quality. Journal of Marketing, 58(1), 125-131.

[6] Ding, D.X., Hu, P.J.-H. \& Sheng, O.R.L. (2011). e-SELFQUAL: a scale for measuring online self-service quality. Journal of Business Research, 64(5), 508-515.

[7] Elliot, S., \& Fowell, S. (2000). Expectations versus reality: A snapshot of consumer experiences with internet retailing. International Journal of Information Management, 20, 323-336.

[8] Francis, J.E., \& White, L. (2002). PIRQUAL: a scale for measuring customer expectations and perceptions of quality in internet retailing. In Evans, K.R., \& Scheer, L.K. (Eds.), Proceedings of the 2002 American Marketing Association Winter Educators' Conference: Marketing Theory and Applications, American Marketing Association, Chicago, IL, 263-270.

[9] Grewal, R., Cote, J. A., \& Baumgartner, H. (2004). Multicollinearity and measurement error in structural equation models: Implications for theory testing, Marketing Science, 23(4), 519-529.

[10] Gronroos, C. (1984). A service quality model and its marketing implications. European Journal of Marketing, 18(4), 36-44.

[11] Hair, J. E. Jr., Black, W. C., Babin, B. J., \& Anderson, R. E. (2009). Multivariate Data Analysis, $7^{\text {th }}$ Edition, Upper Saddle River, NJ: Prentice Hall.

[12] Ho, R. (2006). Handbook of univariate and multivariate data analysis and interpretation with SPSS, Chapman \& Hall/CRC.

[13] Kim, M., Kim, J.-H. \& Lennon, S.J. (2006). Online service attributes available on apparel web sites: an E-SQUAL approach, Managing Service Quality, 16(1), 51-77.

[14] Lehtinen, J.R., \& Lehtinen, U. (1982). Service quality: a study of quality dimensions. Working Paper, Service Management Institute, Helsinki.

[15] Loiacono, E., Watson, R.T. \& Goodhue, D. (2000). WebQual: a web site quality instrument. Working paper, Worcester Polytechnic Institute, Worcester, MA.

[16] Nunnally, J. C. (1978). Psychometric theory, 2nd Edition, New York: McGraw-Hill.

[17] Parasuraman, A., Berry, L. L., \& Zeithaml, V.A. (1988). SERVQUAL: A Multiple-ltem Scale for Measuring Consumer Perceptions of Service Quality. Journal of Retailing, 64(1), $12-40$.

[18] Parasuraman, A., Zeithaml, V.A. \& Malhotra, A. (2005). E-S-QUAL: a multiple item scale for assessing electronic service quality. Journal of Service Research, 7(3), 213-233.

[19] Santos, J. (2003). E-service Quality: A model of Virtual Service Quality Dimensions. Managing Service Quality, 13(3), 233-246.

[20] Zeithaml, V.A., Parasuraman, A. \& Malhotra, A. (2000). A conceptual framework for understanding e-service quality: implications for future research and managerial practice. Working paper, Report No. 00-115, Marketing Science Institute, Cambridge, MA.

[21] Zeithaml, V.A., Parasuraman, A., \& Malhotra, A. (2002). Service quality delivery through web sites: A critical review of extant knowledge. Journal of the Academy of Marketing Science, 30(4), 362-375. 